\title{
EDITORIAL
}

\section{Neonatal pain treatment: ethical to be effective}

\section{Journal of Perinatology (2008) 28, 87-88; doi:10.1038/sj.jp.7211899}

A recent survey on the state of neonatal analgesic treatment in British hospitals has shown that pain in newborns is not yet treated well enough. ${ }^{1}$ Similar unsatisfactory results are reported in other western countries. ${ }^{2,3}$ A previous report from $2000^{4}$ showed, among other data, that only $5 \%$ of units routinely used analgesia for commonly painful procedures such as venipuncture, central catheter line insertion, versus 35\% reported in the present article. This increase is positive but remains unsatisfying. The authors of the current article are also concerned regarding this apparent delay as they write: 'The reason that clinicians are so slow at taking up the routine use of analgesia is not clear when well-designed studies show a clear benefit to patients'. They suppose that better training in analgesic procedures will increase use of agents to ameliorate pain, but we are not as sure as pain treatment has some 'special' features that make it different from the treatment of other conditions.

Here we discuss three reasons that make neonatal pain 'different', and that may account for the resistance towards neonatal analgesia.

\section{Legal reasons}

So called 'defensive medicine' lays at the basis of many clinical decisions. ${ }^{5}$ The concern about legal consequences leads physicians to avoid liability, sometimes using unnecessary laboratory studies. However, defensive medicine has another drawback, that is, when the risk for legal consequences is low, ${ }^{6}$ then misconduct may be more frequent. This is the case for pain, as when a correlation between a painful procedure and harm is not demonstrable then those who provoke unjustified pain are not at risk of legal consequences. ${ }^{7}$ Consequently, in contrast with other harmful conditions, caregivers may feel less moral urgency in providing analgesia.

\section{Vitality}

Until recent years most efforts in neonatal medicine have been devoted to promotion of the newborn's survival rather than wellbeing. ${ }^{8}$ The fear to invest too much in the care of babies with precarious vitality may have been a psychological brake for neonatologists to treat them as owners of full human rights worthy of comprehensive care rather than simple subjects worthy of only cure. Indeed, the current definition of pain made by the IASP in 1991, reflects this difficulty to consider preverbal patients as 'persons', 'because it does not apply to patients that are incapable of self-report'.

\section{Empathy}

The notion that newborns are neurobiologically social ${ }^{10}$ is not yet evident in everyday clinical activity, though recent research demonstrated that we can exploit this attribute to offer newborns a more humane care. For instance, sensitivity to the critically-ill infant's need of relationship enhances the power of nonpharmacological analgesia ${ }^{11}$ and decreases brain damage. ${ }^{12} \mathrm{We}$ cannot struggle against pain if we do not consider newborns' wishes, fears and attempts to communicate. Alternatively, analgesia without reassurance, distraction, comfort and empathy is misbalanced and weak.

Neonatal pain has long time been denied. As recently as 20 years ago most anesthesiologists declared that newborns could feel no pain ${ }^{13}$ and only few used opioids even for major surgery. ${ }^{13}$ Neonatal pain treatment is now widely accepted but much work is still to be done. For instance, as noted by McKechnie and Levene, ${ }^{1}$ staff turnover is high and knowledge dissipates rapidly in such circumstances. These authors suggest that in these circumstances oral communication of pain guidelines may be insufficient and state that increased use of written guidelines will optimize knowledge transfer between caregiving staff.

We believe that a prerequisite should be full acknowledgement of a newborn's personhood, that is, entitlement not only to analgesics, but also to care, comfort and respect. This might make caregivers already familiar with newborns, with their language and their pain, even more sensitive as then the caregivers will recognize subtle and hidden sources of pain (for example, noise, isolation and lights). It will also amplify the power of analgesic treatments as shown by the analgesic effect of maternal breastfeeding or cuddles. ${ }^{14}$ This will cost great effort, because 'caring for (...) patients who do not comprehend the purpose of the physician-patient interaction may render physicians vulnerable to losing empathy with their patients and objectifying them. This can lead to viewing patients as collections of symptoms rather than as humans suffering with illnesses and burdens, ${ }^{15}$ But this is the challenge of neonatal pain treatment, which stimulates our ability of seeing beyond the appearance of an almost uncommunicative patient. 
CV Bellieni ${ }^{1}$ and $\mathrm{G}$ Buonocore ${ }^{2}$ ${ }^{1}$ Bioethics Centre, University of Siena, Siena, Italy and ${ }^{2}$ Department of Pediatrics, Obstetrics and Reproduction Medicine, University of Siena, Siena, Italy E-mail: c.bellieni@tin.it

\section{References}

1 McKechnie L, Levene M. Procedural pain guidelines for the newborn in the United Kingdom. J Perinatol 2007 e-pub ahead of print 13 September.

2 Lago P, Guadagni A, Merazzi D, Ancora G, Bellieni CV, Cavazza A. Pain management in the neonatal intensive care unit: a National survey in Italy. Pediatr Anaesth 2005; 15(11): 925

3 Harrison D, Loughnan P, Johnston L. Pain assessment and procedural pain management practices in neonatal units in Australia. J Paediatr Child Health 2006; 42: $6-9$.

4 Sabrine N, Sinha S. Pain in neonates. Lancet 2000; 355: 932-933.

5 Cunningham $W$, Dovey S. Defensive changes in medical practice and the complaints process: a qualitative study of New Zealand doctors. $N$ Z Med J 2006 Oct 27;119(1244):U2283.
6 Brennan F, Carr DB, Cousins M. Pain management: a fundamental human right. Anesth Analg 2007; 105: 205-221.

7 Bentham J In: Burns JH, Hart HLA, (eds). An Introduction to the Principles of Morals and Legislation. Clarendon Press: 0xford, 1996; 343

8 Shechter N. Evolution of Pediatric Pain Treatment In: Schmidt RF, Willis WD (eds) Encyclopedia of Pain,. Springer, New York, 2007; 749-752.

9 Anand KJS, Craig KD. New perspectives on the definition of pain. Pain 1996; 67 $3-6$.

10 Als H, Duffy FH, McAnulty GB. Effectiveness of individualized neurodevelopmental care in the newborn intensive care unit (NICU). Acta Paediatr 1996; 416(Suppl): 21-30.

11 Shah PS, Aliwalas L, Shah V. Breastfeeding or breastmilk to alleviate procedural pain in neonates: a systematic review. Breastfeed Med 2007; 2(2): 74-82.

12 Als H, Duffy FH, McAnulty GB, Rivkin MJ, Vajapeyam S, Mulkern RV et al. Early experience alters brain function and structure. Pediatrics 2004; 113(4): 846-857.

13 DeLima J, Lloyd-Thomas AR, Howard RF, Summer E, Quinn TM. Infant and neonatal pain : anaesthetists' perceptions and prescribing patterns. BMJ 1996; 313: 787.

14 Bellieni CV, Bagnoli F, Buonocore G. Alone no more: pain in premature children Ethics Med 2003; 19(1): 5-9.

15 Blass DM. The physician-patient relationship in dementia care. Neurotherapeutics 2007; 4(3): $545-548$. 